\title{
Segregation and trapping of erbium during silicon molecular beam epitaxy
}

\author{
R. Serna, ${ }^{\text {a) }}$ M. Lohmeier, P. M. Zagwijn, E. Vlieg, and A. Polman \\ FOM-Institute for Atomic and Molecular Physics, Kruislaan 407, 1098 SJ Amsterdam, \\ The Netherlands
}

(Received 21 November 1994; accepted for publication 17 December 1994)

\begin{abstract}
Erbium surface segregation is observed during growth of Er-doped Si by molecular beam epitaxy on $\mathrm{Si}(100)$ at $600{ }^{\circ} \mathrm{C}$. Once a critical Er surface areal density of $2 \times 10^{14} \mathrm{Er} / \mathrm{cm}^{2}$ is reached, enhanced Er trapping is observed, possibly due to the formation of silicide precipitates. Er segregation on $\mathrm{Si}(100)$ is fully avoided when growth is performed in an oxygen background pressure of $10^{-10} \mathrm{mbar}$, due to the formation of Er-O complexes. No Er segregation is observed on $\mathrm{Si}(111)$, which is attributed to the formation of epitaxial $\mathrm{Er}_{3} \mathrm{Si}_{5}$ precipitates. (C) 1995 American Institute of Physics.
\end{abstract}

A number of papers have been published lately on the optical doping of silicon with erbium. The aim is to obtain light emitting devices using the luminescence of the $\mathrm{Er}^{3+}$ ion at $1.5 \mu \mathrm{m}$, a standard communication wavelength. In order to obtain efficient devices $\mathrm{Er}$ concentrations of at least $10^{18} / \mathrm{cm}^{3}$ are needed. ${ }^{1}$ As the use of near-equilibrium crystal growth methods limits the rare-earth incorporation to the maximum solid solubility, nonequilibrium techniques have been used, e.g., ion implantation either directly into crystalline $\mathrm{Si}^{2-7}$ or during molecular beam epitaxy (MBE) ${ }^{8}$ Incorporation of Er by ion implantation induces amorphization of the Si crystal. During solid phase epitaxy (SPE) of the Erdoped amorphous $\mathrm{Si}$, segregation and trapping takes place, and up to $10^{20} \mathrm{Er} / \mathrm{cm}^{3}$ can be incorporated in the crystalline $\mathrm{Si}^{5,6} \mathrm{MBE}$ coevaporation of $\mathrm{Si}$ and Er offers the opportunity to grow in a direct way thick Er-doped layers. There are a few reports on Er doping by MBE, ${ }^{9-11}$ however the kinetics of incorporation and its limiting factors have not been studied in detail. In this letter, it will be shown that strong Er surface segregation occurs during MBE on $\mathrm{Si}(100)$, which is avoided when introducing an oxygen background pressure during growth. No segregation is observed on $\mathrm{Si}(111)$.

Erbium-doped epitaxial Si layers were grown in a MBE apparatus utilizing an electron beam evaporator for $\mathrm{Si}$ and a Knudsen cell for coevaporation of Er. The Si flux was $1.5 \times 10^{14}$ atoms $/ \mathrm{cm}^{2} \mathrm{~s}$ in all cases. The Er flux was varied in the $3-14 \times 10^{10}$ atoms $/ \mathrm{cm}^{2} \mathrm{~s}$ range by regulating the Knudsen cell temperature between 1030 and $1100{ }^{\circ} \mathrm{C}$. Float zone $\mathrm{Si}(100)$ or $\mathrm{Si}(111)$ crystals were used as substrates. The native oxide on the $\mathrm{Si}$ surface was removed by briefly heating the sample to $1100{ }^{\circ} \mathrm{C}$ in ultrahigh vacuum (base pressure $\left.3 \times 10^{-11} \mathrm{mbar}\right)$. After this treatment the surface exhibited a clear $2 \times 1[\mathrm{Si}(100)]$ or $7 \times 7$ [Si(111)] reflection high-energy electron diffraction pattern. A $20 \mathrm{~nm}$ thick $\mathrm{Si}$ buffer layer was first grown before opening the Er Knudsen cell to ensure good initial epitaxy. Subsequently, codeposition of $\mathrm{Er}$ and $\mathrm{Si}$ was performed, resulting in a $\approx 100 \mathrm{~nm}$ thick Er-doped film. Typical growth pressures during deposition were $6 \times 10^{-11} \mathrm{mbar}$, and the substrate temperature was kept at $600{ }^{\circ} \mathrm{C}$. In order to study the role of oxygen in

\footnotetext{
${ }^{a)}$ Present address: Instituto de Optica, CSIC, Serrano 121, 28006 Madrid, Spain.
}

the Er-doping, oxygen was introduced in the MBE chamber through a needle valve. The Er concentration depth profiles, layer thickness, and $\mathrm{Si}$ crystal quality were measured with Rutherford backscattering spectrometry (RBS)/channeling using $2 \mathrm{MeV} \mathrm{He}$. A backscattering angle of $100^{\circ}$ was used to give a depth resolution better than $10 \mathrm{~nm}$.

Figure 1 shows RBS channeling and random spectra for a sample grown with an $\mathrm{Er}$ flux of 3.1 $\times 10^{10}$ atoms $/ \mathrm{cm}^{2} \mathrm{~s}$. The channeling minimum yield in the as-grown layer is $\chi_{\min }<3 \%$, indicating good crystal quality. A clear surface peak is observed for the Er signal, which accounts for $78 \%$ of the total amount of deposited Er. These data show that strong surface segregation takes place during growth. The profile shows a monotonic increase of the $\mathrm{Er}$ bulk concentration from the substrate interface towards the surface up to $4 \times 10^{18} \mathrm{Er} / \mathrm{cm}^{3}$. The profiles for the channeling and random configurations overlap, indicating that $\mathrm{Er}$ is not in Si lattice positions, nor in tetrahedral interstitial sites.

To have a further insight in the kinetics of the segregation process, Fig. 2(a) shows the Er profiles from RBS for the $100 \mathrm{~nm}$ thick film from Fig. 1, and for a thinner film

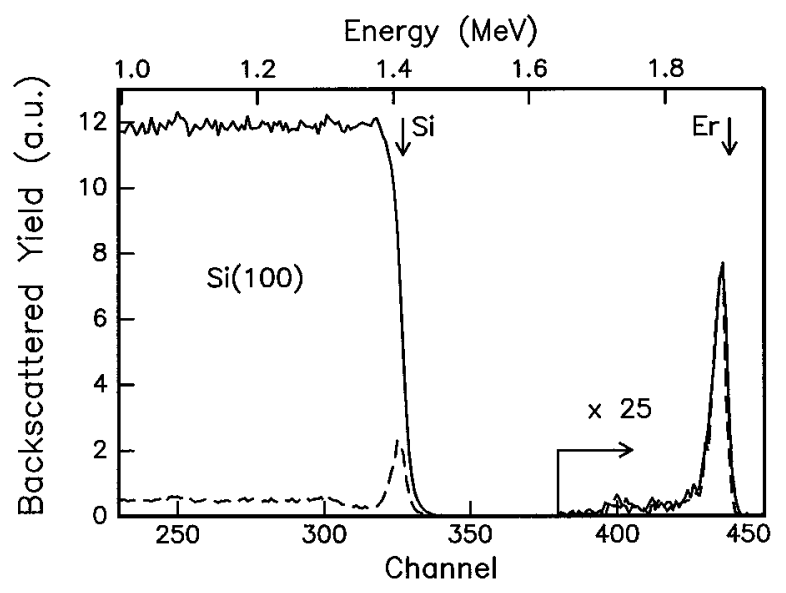

FIG. 1. RBS random (solid line) and channeling (dashed line) spectra for an Er-doped MBE film grown on $\mathrm{Si}(100)$ at $600{ }^{\circ} \mathrm{C}$. Er and $\mathrm{Si}$ fluxes were $3.1 \times 10^{10}$ and $1.5 \times 10^{14}$ atoms $/ \mathrm{cm}^{2} \mathrm{~s}$, respectively. The Er signal is magnified by a factor of 25 . The arrows indicate the surface channels for $\mathrm{Si}$ and Er. 


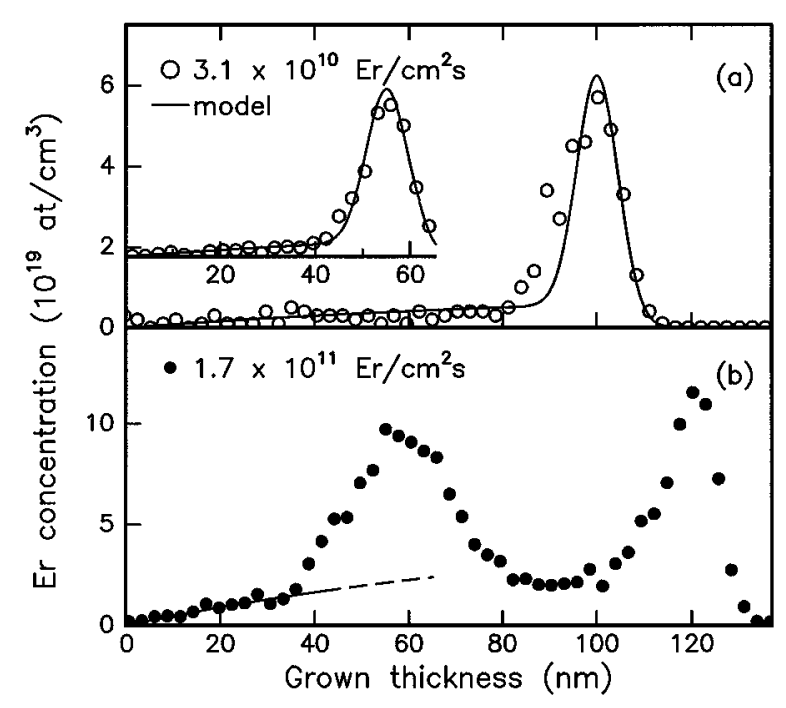

FIG. 2. Er concentration as a function of thickness for MBE films on $\mathrm{Si}(100)$ at $600^{\circ} \mathrm{C}$. The Er flux was $3.1 \times 10^{10}$ atoms $/ \mathrm{cm}^{2} \mathrm{~s}$ (a), or 1.7 $\times 10^{11} / \mathrm{cm}^{2} \mathrm{~s}(\mathrm{~b})$. The data of the thin sample in (a) are offset vertically to facilitate comparison. In this figure the horizontal scale has been converted to grown thickness of the Si film. Therefore, the Er surface peaks appear at different thickness. The full lines are the calculated profiles according to a kinetic two-dimensional growth and segregation model

$(\sim 55 \mathrm{~nm})$ grown under the same conditions. The profile of the thin film is identical to the thick one in the first $40 \mathrm{~nm}$. As the growth is stopped in an earlier stage the surface peak is smaller. The Er profiles of Fig. 2(a) can be very well described by a kinetic two-dimensional growth and surface segregation model. This model assumes that there is a small incorporation probability $(\alpha)$ of $\mathrm{Er}$ for each monolayer of growing crystal, due to the low solubility of $\mathrm{Er}$ in $\mathrm{Si}$. The Er can escape from being incorporated in the crystal via a "step-climbing process" at the surface during growth. Assuming no desorption takes place, the Er bulk concentration $N_{b}$ as a function of the distance $z$ from the Si substrate interface is then given by: ${ }^{12}$

$$
N_{b}(z)=\frac{F_{d}}{\nu_{g}}\left(1-e^{-z / \Delta}\right),
$$

where $F_{d}$ is the dopant flux, and $\nu_{g}$ is the growth rate. The parameter $\Delta=h / \alpha$ is the characteristic film thickness required to reach steady-state doping, with $h$ the step height. At each point during growth the surface areal density of segregated $\mathrm{Er}, N_{s}$, is then proportional to the concentration trapped in the crystal

$$
N_{s}(z)=N_{b}(z) \frac{h}{\alpha} .
$$

The higher the surface step or the lower the incorporation probability, the higher will be the density of segregated Er. In Fig. 2(a) the calculation performed with this model is overlaid for the two samples. The data are convoluted with a depth resolution of $8 \mathrm{~nm}$. Good agreement with the experimental data is obtained in both cases for an incorporation probability of $\alpha=1.5 \times 10^{-3}$.

Figure 2(b) shows the Er profile for a sample grown with a higher Er flux, $1.7 \times 10^{11}$ atoms $/ \mathrm{cm}^{2} \mathrm{~s}$. The model de- scribed above fits these data with the same value for $\alpha$ [drawn line in Fig. 2(b)], until a sharp increase in the bulk concentration takes place at a thickness of about $35 \mathrm{~nm}$. At this point the Er concentration suddenly increases, from $\sim 2 \times 10^{19}$ to $1 \times 10^{20} / \mathrm{cm}^{3}$. After this maximum the $\mathrm{Er}$ concentration decreases again and finally an Er peak is observed at the surface. Good channeling is achieved for this film $\left(\chi_{\min }=3 \%\right)$, indicating that the Si crystal quality is still good. A similar behavior has been observed for other $\mathrm{Er}$ fluxes higher than $7 \times 10^{10}$ atoms $/ \mathrm{cm}^{2} \mathrm{~s}$. A possible explanation of this incorporation instability is that erbium silicide precipitates are formed when the Er surface areal density reaches a critical value. A large fraction of the segregated $\mathrm{Er}$ is then suddenly incorporated in the crystal, and therefore the amount of Er at the surface decreases. Subsequently, the segregation process continues, and the Er concentration at the surface increases again. This model implies that when thicker films are grown, or higher Er fluxes are used, an oscillatory change in the growth mode will be observed, resulting in a depth modulation of the precipitates density. Figure 2(b) shows that the maximum Er concentration which can be incorporated by $\mathrm{MBE}$ without precipitation at $600{ }^{\circ} \mathrm{C}$ is $2 \times 10^{19} \mathrm{Er} / \mathrm{cm}^{3}$. The corresponding areal density [from Eq. (2)] is $\sim 2 \times 10^{14} \mathrm{Er} / \mathrm{cm}^{2}$ (a coverage of about $30 \%$ ). This is the threshold areal density above which the instability takes place. Such a high surface Er coverage is not achieved for the low Er flux, in which case the incorporation remains stable. The formation of silicide precipitates has been observed earlier in Er-doped films grown by MBE. ${ }^{9,10}$ However, our data indicate that these precipitation phenomena during MBE have a kinetic rather than a pure thermodynamic origin. 9,10

It is interesting to note the analogy with Er incorporation by ion implantation and SPE at $600^{\circ} \mathrm{C}$. During SPE segregation of the $\mathrm{Er}$ is also observed, the incorporation also becomes unstable, though for larger concentrations (1.2 $\times 10^{20} \mathrm{Er} / \mathrm{cm}^{3}$ ), and is accompanied by the formation of crystal twins. ${ }^{5}$ In the MBE case the Er which is not incorporated in the crystal segregates towards a free surface, whereas in the case of SPE the excess Er is incorporated in the amorphous phase and distributed in a $\sim 3 \mathrm{~nm}$ thick segregation spike, ${ }^{6}$ thus allowing a higher segregated Er density before precipitation takes place.

Oxygen has a large influence on the Er segregation behavior during MBE. Figure 3 shows the Er depth profile after $\mathrm{MBE}$ on $\mathrm{Si}(100)$ in an oxygen ambient of 4 $\times 10^{-10}$ mbar, and the profile after MBE without oxygen at the same $\mathrm{Si}$ and Er rates [Fig. 2(a)]. The area under both curves is the same, and evaluates to a total areal density $1.0 \times 10^{14} \mathrm{Er} / \mathrm{cm}^{2}$. The channeling minimum yield for the film grown in an oxygen background is as good as that obtained for the films grown without oxygen $\left(\chi_{\min }<3 \%\right)$. From the profile it can be seen that after a transient $(\approx 50 \mathrm{~nm})$, during which the Er concentration gradually increases, a final steady-state concentration of $1.5 \times 10^{19} / \mathrm{cm}^{3}$ is reached.

It has been shown that oxygen can play an important role in the optical activation of $\mathrm{Er}$ in $\mathrm{Si}^{3,4,7,11,13}$ The important reduction in the segregation of Er induced by oxygen during $\mathrm{MBE}$ growth is an additional advantage of the codoping with 


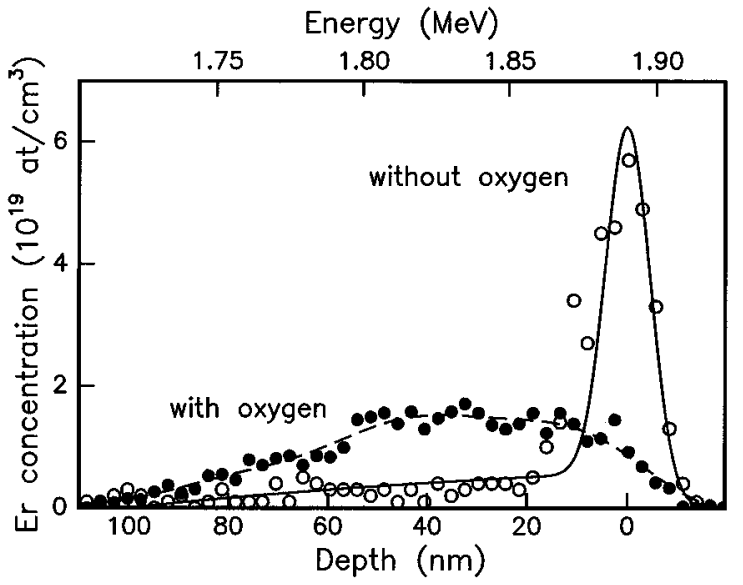

FIG. 3. Er concentration depth profile of a MBE film grown on $\mathrm{Si}(100)$ at $600{ }^{\circ} \mathrm{C}$, at an oxygen background pressure of $4 \times 10^{-10}$ mbar. The Er flux was $3.1 \times 10^{10} / \mathrm{cm}^{2} \mathrm{~s}$ (full circles). The Er profile of the corresponding film grown without oxygen (background pressure $<6 \times 10^{-11} \mathrm{mbar}$ ) is included for reference (open circles). The dashed line is a guide for the eye.

oxygen. The fact that the dopant profile is very sensitive to oxygen contamination may explain why Er segregation has not been reported previously. The increased Er incorporation in the presence of oxygen may have two different origins. First, it may be that $\mathrm{O}$ influences the growth for example by decreasing the adatom mobility, or changing the energy barrier to climb steps. ${ }^{14}$ Second, O may react with $\mathrm{Er}$ at the $\mathrm{Si}$ surface forming complexes which can be easily incorporated. Extended x-ray absorption fine-structure measurements have shown the existence of such complexes in Er-implanted $\mathrm{Si}$, codoped with $\mathrm{O} .{ }^{15}$ In addition, measurements of the $1.53 \mu \mathrm{m}$ photoluminescence performed for both samples in Fig. 3 show a distinctly different spectrum and luminescence lifetime, consistent with the fact that Er-O complexes have formed. ${ }^{16}$ Note that $\mathrm{O}$ also reduces Er segregation during $\mathrm{Si}$ $\mathrm{SPE} ;{ }^{6,7}$ indeed, the presence of $\mathrm{O}$ increases the effective solubility of Er in crystal $\mathrm{Si}^{17}$

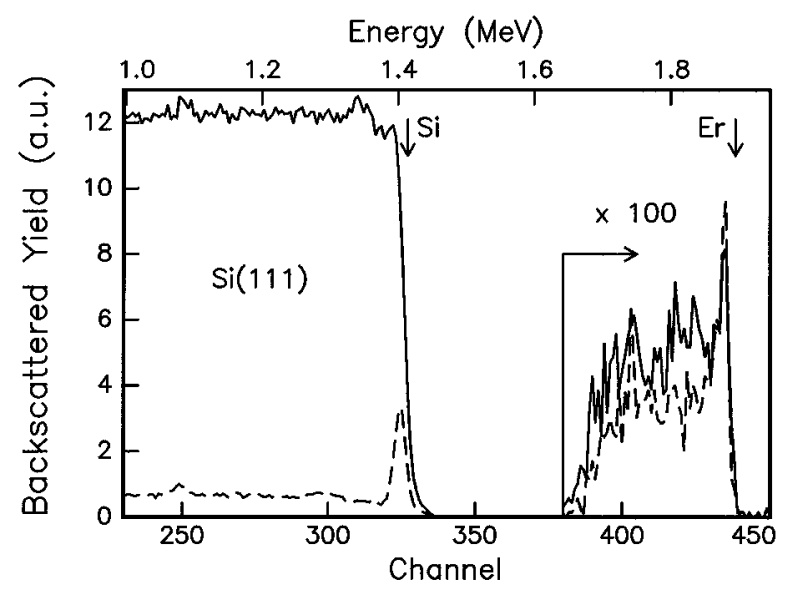

FIG. 4. RBS random (solid line) and channeling (dashed line) spectra for a MBE film grown on $\mathrm{Si}(111)$ at $600^{\circ} \mathrm{C}$. The $\mathrm{Er}$ flux was 3.1 $\times 10^{10} / \mathrm{cm}^{2} \mathrm{~s}$. Channeling was performed in the [111] direction. The Er signal is magnified by a factor of 100 . The arrows indicate the surface channels for Si and Er.
Er incorporation is very different during growth on $\mathrm{Si}(111)$. Figure 4 shows the RBS spectra taken in channeling and random conditions for a film grown on $\mathrm{Si}(111)$ under the same conditions as the film on $\mathrm{Si}(100)$ in Fig. 1. The channeling minimum yield for the film in the [111] direction shows a good epitaxial quality $\left(\chi_{\min }<3 \%\right)$. From the figure it is apparent that for $\mathrm{Si}(111)$ without oxygen there is almost no Er segregation. The Er yield in the channeling spectrum is $29 \%$ lower than in the random spectrum. This indicates that this fraction of Er atoms is located in ordered positions relative to the [111] direction. We attribute this strong difference in the Er doping mode on $\mathrm{Si}(111)$ to the formation of epitaxial silicide precipitates. It is known that $\mathrm{Er}_{3} \mathrm{Si}_{5}(0001)$ can be grown epitaxially on $\mathrm{Si}(111)$, with a lattice mismatch of only $1.22 \% .^{18}$

In conclusion, we have shown that strong Er segregation takes place during $\mathrm{Si} \mathrm{MBE}$ with Er coevaporation on $\mathrm{Si}(100)$. Once a critical $\mathrm{Er}$ surface areal density of 2 $\times 10^{14} \mathrm{Er} / \mathrm{cm}^{2}$ is achieved, an instability in the segregation/ incorporation process takes place. The segregation can be completely suppressed by the presence of oxygen during deposition, possibly due to the formation of Er-O complexes. During MBE on $\mathrm{Si}(111)$ no Er segregation is observed, which is attributed to the growth of epitaxial erbium silicide precipitates.

We gratefully acknowledge discussions with $\mathrm{H}$. A. van der Vegt. This work is part of the research program of FOM and was made possible by financial support from NWO, STW, and IOP Electro-Optics. R. Serna acknowledges financial support from CSIC, Spain.

${ }^{1}$ Y. H. Xie, E. A. Fitzgerald, and Y. J. Mii, J. Appl. Phys. 70, 3223 (1991). ${ }^{2}$ H. Ennen, J. Schneider, G. Pomrenke, and A. Axmann, Appl. Phys. Lett. 43, 943 (1983).

${ }^{3}$ P. N. Favenec, H. L'Haridon, D. Moutonnet, M. Salvi, and M. Gauneau, Jpn. J. Appl. Phys. 29, L521 (1990).

${ }^{4}$ J. Michel, J. L. Benton, R. F. Ferrante, D. C. Jacobson, D. J. Eaglesham, E. A. Fitzgerald, Y.-H. Xie, J. M. Poate, and L. C. Kimerling, J. Appl. Phys. 70, 2672 (1991).

${ }^{5}$ A. Polman, J. S. Custer, E. Snoeks, and G. N. van den Hoven, Appl. Phys. Lett. 62, 507 (1993).

${ }^{6}$ J. S. Custer, A. Polman, and H. M. van Pinxteren, J. Appl. Phys. 75, 2809 (1994).

${ }^{7}$ F. Priolo, S. Coffa, G. Franzó, C. Spinella, A. Carnera, and V. Bellani, J. Appl. Phys. 74, 4936 (1993).

${ }^{8}$ H. Ennen, G. Pomrenke, A. Axmann, K. Eisele, W. Haydl, and J. Schneider, Appl. Phys. Lett. 46, 381 (1985).

${ }^{9}$ H. Efeogiu, J. H. Evans, J. M. Langert, A. R. Peaker, N. L. Rowel, J. P. Noel, D. D. Perovic, T. E. Jackman, and D. C. Hougton, Mater. Res. Soc. Proc. 220, 367 (1991).

${ }^{10}$ H. E. Efeogiu et al., Semicond. Sci. Technol. 8, 238 (1993).

${ }^{11}$ F. Arnaud D'Avitaya, Y. Campidelli, J. A. Chroboczek, P. N. Favenec, H. L'Haridon, D. Moutonnet, and A. Wasiela, Mater. Res. Soc. Symp. Proc. 301, 97 (1993).

${ }^{12}$ S. Andrieu, F. Arnaud d'Avitaya, and J. C. Pfister, J. Appl. Phys. 65, 2687 (1989).

${ }^{13}$ S. Coffa, G. Franzó, F. Priolo, A. Polman, and R. Serna, Phys. Rev. B 49, 16313 (1994).

${ }^{14}$ S. Esch, M. Hohage, T. Michely, and G. Comsa, Phys. Rev. Lett. 72, 518 (1994).

${ }^{15}$ D. L. Adler, D. C. Jacobson, D. C. Eaglesham, M. A. Marcus, J. L. Benton, J. M. Poate, and P. H. Citrin, Appl. Phys. Lett. 61, 2181 (1992).

${ }^{16}$ R. Serna, J. H. Shin, A. Polman, M. Lohmeier, and E. Vlieg (unpublished).

${ }^{17}$ A. Polman, G. N. van de Hoven, J. S. Custer, J. H. Shin, R. Serna, and P. F. A. Alkemade, J. Appl. Phys. 77, 1256 (1995).

${ }^{18}$ J. A. Knapp and S. T. Picraux, Appl. Phys. Lett. 48, 466 (1986). 